\title{
Utility of the E/e' index in ventilated patients and those with sepsis
}

\author{
Imran Sunderji ${ }^{1}$ and Alan Fraser ${ }^{2}$ \\ ${ }^{1}$ Hull University Teaching Hospitals NHS Trust \\ ${ }^{2}$ University Hospital of Wales
}

October 20, 2020

\section{Utility of the E/e' index in ventilated patients and those with sepsis}

Imran Sunderji ${ }^{1}$, Alan G Fraser ${ }^{2}$

(Reply to the letter from Filippo Sanfilippo and colleagues, ECHO-2020-0930)

${ }^{1}$ Department of Cardiology, Castle Hill Hospital, Hull, U.K.

${ }^{2}$ Department of Cardiology, University Hospital of Wales, Cardiff, U.K.

Address for correspondence :

Professor Alan G. Fraser,

University Hospital of Wales,

Heath Park,

Cardiff, CF14 4XW,

Wales, U.K.

fraserag@cf.ac.uk

Telephone: +44 (0)2920745366

Fax: +44 (0)29 20744473

915 words

We thank Sanfilippo and his colleagues for their interest in our paper, and for the opportunity thus afforded to comment on the $\mathrm{E} / \mathrm{e}$ ' index in critically ill patients and in those who have severe sepsis.

We agree that the $\mathrm{E} / \mathrm{e}^{\prime}$ index has some utility in predicting successful weaning from mechanical ventilation, as they have shown in their most recent meta-analysis, ${ }^{1}$ but published studies show high heterogeneity, there are often only small initial differences in mean E/e' between patients who will remain off ventilation and those who will not, and average $\mathrm{E} / \mathrm{e}$ ' values in both groups are sometimes within normal or intermediate ranges. Earlier systematic reviews also concluded that a higher E/e' ratio is associated with weaning failure in ventilated patients ${ }^{2}$ and that $\mathrm{E} / \mathrm{e}^{\prime}$ (as well as other markers of diastolic dysfunction) predicts mortality in critically ill patients. ${ }^{3}$ In a large study of 161 patients, however, neither E/e' at the lateral mitral annulus nor any other echocardiographic index predicted success in weaning. ${ }^{4}$ The heterogeneity of criteria for diastolic dysfunction in these studies is illustrated by cut-points for abnormal E/e' varying between 8 and 12 at the lateral mitral annulus and 8 and 9.6 at the medial (septal) annulus. ${ }^{3}$

In ventilated as in other patients, both $\mathrm{E}$ and $\mathrm{e}$ ' are preload-dependent. ${ }^{5}$ Positive end-expiratory pressure (PEEP) reduces both; for example PEEP of $12 \mathrm{~cm} \mathrm{H}_{2} \mathrm{O}$ decreased lateral e' by $19.7 \%$ and $\mathrm{E}$ by $13.7 \%$, so 
E/e' was unchanged. ${ }^{6}$ An increase in e' when a patient is taken off a ventilator could indicate a response to changed loading rather than an improvement in intrinsic diastolic function. Before concluding that observed changes in E/e' imply corresponding changes in left ventricular (LV) filling pressures, we should consider if $\mathrm{E} / \mathrm{e}$ ' has been validated by correlation with pulmonary capilllary wedge pressure (PCW) measured with Swan Ganz catheters, specifically in ventilated and critically ill patients.

In 39 patients there was no difference in $\mathrm{E} / \mathrm{e}$ ' before a trial of spontaneous breathing, between those subjects in whom it was successful (defined as PCW remaining $<18 \mathrm{mmHg}$ after 60 minutes; mean baseline E/e' 8.0) and those in whom it was not (PCW increasing to $>18 \mathrm{mmHg}$; baseline E/e' 7.6). ${ }^{7}$ The area under the receiver operating characteristic curve (AUC) for E/e' as a guide to $\mathrm{PCW}$ at the end of the trial of spontaneous breathing was 0.8. In an earlier study of patients in intensive care who were also breathing spontaneously, E/e' had a modest correlation with $\mathrm{PCW}(\mathrm{r}=0.69)$; a patient with E/e' of around 10 could have a $\mathrm{PCW}$ ranging from $<10$ to $>20 \mathrm{mmHg} .{ }^{8}$ In other studies of ventilated patients, the correlation of lateral E/e' with PCW was $0.84^{9}$ and its AUC was $0.91 .{ }^{10}$ Recently, Brault et al reported that the 2016 American Society of Echocardiography and European Association of Cardiovascular Imaging guidelines for diastolic dysfunction did not accurately assess PCW in 98 ventilated and critically ill patients, of whom $54 \%$ experienced septic shock. The diagnostic score was indeterminate in $49 \%$ of patients, sensitivity and specificity were both $74 \%$, and agreement between echocardiography and PCW was moderate (Cohen's Kappa, 0.48). The best echocardiographic predictor of a normal PCW was not the E/e' ratio but a lateral $\mathrm{e}^{\prime}>8 .{ }^{11}$

From experimental and clinical observations it is clear that severe sepsis can depress myocardial contractile function, probably through multiple mechanisms. ${ }^{12}$ In 40 patients with sepsis, however, there were no significant correlations between serum concentrations of inflammatory cytokines and measurements of e' or calculated E/e'. ${ }^{13}$ In another study, mortality was predicted by the APACHE II score and mitral annular systolic excursion (MAPSE) with an AUC of 0.88 , while the E/e' index was not selected as a predictor in a logistic regression analysis. ${ }^{14}$ Reproducibility of echocardiographic measurements in patients with septic shock is moderate to good ${ }^{15}$ but it is difficult to rely on single observations to guide clinical decisions.

In patients with sepsis and severe diastolic dysfunction, failure to respond to volume replacement may be caused by impaired early diastolic relaxation and LV suction, which cannot be detected by the E/e' index. In a randomised trial, an intravenous infusion of esmolol to slow the heart rate prolonged LV filling and increased stroke volume, with a subsequent reduction in mortality. ${ }^{16}$ In a prospective observational study, levosimendan increased the probability of successful weaning from ventilation, and averted any increase in E/e'; ${ }^{17}$ that could also be explained by improved early diastolic relaxation and filling, since levosimendan is positively lusitropic. ${ }^{18}$ Detailed echocardiographic assessment of ventilated patients after cardiac surgery showed that levosimendan increased early diastolic strain rate by $30 \% .{ }^{19}$ Thus changes in E/e' as a marker of mean PCW do not necessarily confirm a causal relationship with any particular aspect of LV diastolic function, while more comprehensive echocardiographic analysis of pathophysiological mechanisms may be more informative.

These thoughts reinforce some of the conclusions that we drew in our review. Many studies are difficult to interpret because the E/e' index is reported without information on changes in its individual components, and because dichotomising patients into normal or diastolic dysfunction (grades) loses information from multiple continuous variables that are inter-related but may change with differing patterns according to particular circumstances. It is unwise to use discrete cut-points especially if they are unadjusted for age and gender, and mistaken to conclude that LV diastolic function has changed when there are significant differences in the E/e' index but its mean values remain within the normal range. The optimal assessment of diastolic dysfunction in septic and ventilated patients requires a multiparametric approach and we caution against over-reliance on E/e'.

\section{References}

1. Sanfilippo F, Di Falco D, Noto A, Santonocito C, Morelli A, Bignami E, Scolletta S, Vieillard-Baron A, 
Astuto M. Association of weaning failure from mechanical ventilation with transthoracic echocardiography parameters: a systematic review and meta-analysis.Br J Anaesth. 2020 Sep 25:S0007-0912(20)30684-X. doi: 10.1016/j.bja.2020.07.059. [e-pub]

2. de Meirelles Almeida CA, Nedel WL, Morais VD, Boniatti MM, de Almeida-Filho OC. Diastolic dysfunction as a predictor of weaning failure: A systematic review and meta-analysis. J Crit Care. 2016;34:135-41.

3. Garry D, Newton J, Colebourn C. Tissue Doppler indices of diastolic function in critically ill patients and association with mortality - a systematic review. J Intensive Care Soc. 2016;17:51-62.

4. Amarja H, Bhuvana K, Sriram S. Prospective observational study on evaluation of cardiac dysfunction induced during the weaning process. Indian J Crit Care Med 2019;23:15-19.

5. Quintard H, Muller L, Philip I, Lena P, Ichai C. Influence of acute preload changes on mitral annulus velocity measured by tissue Doppler echocardiography in critically ill patients. J Clin Ultrasound. 2012;40:419-23.

6. Juhl-Olsen P, Hermansen JF, Frederiksen CA, Rasmussen LA, Jakobsen CJ, Sloth E. Positive endexpiratory pressure influences echocardiographic measures of diastolic function: a randomized, crossover study in cardiac surgery patients. Anesthesiology. 2013;119:1078-86.

7. Lamia B, Maizel J, Ochagavia A, Chemla D, Osman D, Richard C, Teboul JL. Echocardiographic diagnosis of pulmonary artery occlusion pressure elevation during weaning from mechanical ventilation. Crit Care Med. 2009;37:1696-701.

8. Dokainish H, Zoghbi WA, Lakkis NM, Al-Bakshy F, Dhir M, Quinones MA, Nagueh SF. Optimal noninvasive assessment of left ventricular filling pressures: a comparison of tissue Doppler echocardiography and B-type natriuretic peptide in patients with pulmonary artery catheters. Circulation. 2004;109:2432-2439.

9. Combes A, Arnoult F, Trouillet JL. Tissue Doppler imaging estimation of pulmonary artery occlusion pressure in ICU patients. Intensive Care Med. 2004 Jan;30(1):75-81.

10. Vignon P, AitHssain A, François B, Preux PM, Pichon N, Clavel M, Frat JP, Gastinne H. Echocardiographic assessment of pulmonary artery occlusion pressure in ventilated patients: a transoesophageal study. Crit Care. 2008;12(1):R18.

11. Brault C, Marc J, Mercado P, Diouf M, Tribouilloy C, Zerbib Y, Maizel J, Vignon P, Slama M. Estimation of pulmonary artery occlusion pressure using doppler echocardiography in mechanically ventilated patients. Crit Care Med. 2020;48:e943-e950.

12. Martin L, Derwall M, Al Zoubi S, Zechendorf E, Reuter DA, Thiemermann C, Schuerholz T. The septic heart: current understanding of molecular mechanisms and clinical implications. Chest. 2019;155:427-437.

13. Landesberg G, Levin PD, Gilon D, Goodman S, Georgieva M, Weissman C, Jaffe AS, Sprung CL, Barak V. Myocardial dysfunction in severe sepsis and septic shock: no correlation with inflammatory cytokines in real-life clinical setting. Chest. 2015 Jul;148(1):93-102.

14. Havaldar AA. Evaluation of sepsis induced cardiac dysfunction as a predictor of mortality. Cardiovasc Ultrasound. 2018;16(1):31.

15. De Geer L, Oscarsson A, Engvall J. Variability in echocardiographic measurements of left ventricular function in septic shock patients. Cardiovasc Ultrasound. 2015 Apr 15;13:19. doi: 10.1186/s12947-015-0015-6.

16. Morelli A, Ertmer C, Westphal M, Rehberg S, Kampmeier T, Ligges S, Orecchioni A, D'Egidio A, D'Ippoliti F, Raffone C, Venditti M, Guarracino F, Girardis M, Tritapepe L, Pietropaoli P, Mebazaa A, Singer M. Effect of heart rate control with esmolol on hemodynamic and clinical outcomes in patients with septic shock: a randomized clinical trial. JAMA. 2013;310:1683-91. 
17. Kaltsi I, Angelopoulos E, Tzanis G, Sideris A, Tyrovolas K, Kokkoris S, Gratziou C, Nanas S, Routsi C. Contribution of levosimendan in weaning from mechanical ventilation in patients with left ventricular dysfunction: a pilot study. Crit Care Res Pract. 2019:7169492.

18. Jörgensen K, Bech-Hanssen O, Houltz E, Ricksten SE. Effects of levosimendan on left ventricular relaxation and early filling at maintained preload and afterload conditions after aortic valve replacement for aortic stenosis. Circulation. 2008;117:1075-1081.

19. Fredholm M, Jörgensen K, Houltz E, Ricksten S-E. Inotropic and lusitropic effects of levosimendan and milrinone assessed by strain echocardiography - A randomised trial. Acta Anaesthesiol Scand. 2018;62:12461254 . 